\title{
Spatial variation in the chemical composition of natal otoliths from a reef fish in the Galápagos Islands
}

\author{
Benjamin I. Ruttenberg*, Robert R. Warner \\ Department of Ecology, Evolution and Marine Biology, University of California, Santa Barbara, California 93106, USA
}

\begin{abstract}
Over the past decade, researchers have used variation in the chemical composition of fish otoliths (earstones) to address a number of ecological questions, such as stock assessment and assessing rates of movement of individuals among habitats or life-history stages. However, these methods have yet to be applied successfully to the study of larval connectivity, a major unanswered question in marine ecology. Accomplishing this task requires a reference collection of pre-pelagic natal otoliths and accurate measurement of the chemical signatures of otoliths cores of recruits. We analyzed the chemical composition of natal otoliths from near-term benthic eggs of a damselfish (Stegastes beebei) from all regions of the Galápagos Archipelago. There was no consistent variation in chemical signature at the largest scale, among regions in the archipelago (separated by $\sim 100$ to $150 \mathrm{~km})$. However, we found significant variation among islands within each region (10s of $\mathrm{km})$, and among clutches within islands. In addition, we found that otolith cores of newly settled recruits often differed chemically from natal otoliths (which ultimately make up the otolith core as the fish grows). Variation at smaller spatial scales but not larger ones implies that otolith chemistry will only be usable if larvae disperse short distances in this system, and additional work is required to understand the relationship between the chemistry of natal otoliths and recruit cores. Otolith chemistry has the potential to address questions of connectivity, but our data suggest that these methods should be applied cautiously.
\end{abstract}

KEY WORDS: Otolith chemistry · Trace element · LA-ICPMS · Larval dispersal · Galápagos

\section{INTRODUCTION}

In recent years, researchers have been using analyses of the chemistry of otoliths - accretions of calcium carbonate and proteins in the inner ears of fishes - to address a number of ecological questions. These techniques utilize natural variability in the chemical composition of otoliths across life-history stages or among populations. Otoliths are used for hearing and balance and often form daily or annual growth bands that can be used to determine the age of a fish as they grow (see Secor et al. 1995 and references therein). Otoliths also incorporate trace metals into the calcium carbonate matrix at rates that are often related to ambient concentrations and ambient temperatures (Bath et al. 2000, Campana \& Thorrold 2001, Elsdon \& Gillanders
2003). Because otoliths are metabolically inert, once a layer is deposited it apparently forms a permanent record of the conditions a fish experienced at a given time (Campana 1999, Campana \& Thorrold 2001). Although a number of studies have shown that the composition of fish otoliths does not directly reflect the chemistry of the surrounding waters (Hoff \& Fuiman 1995, Martin \& Thorrold 2005, Warner et al. 2005), moderate differences in aquatic chemistry generally result in detectable differences in otolith chemistry, at least for some elements such as strontium and barium (e.g. Bath et al. 2000, Milton \& Chenery 2001, Elsdon \& Gillanders 2003).

Ecological studies of otolith chemistry tend to fall into 2 general categories: (1) attempts to assign individuals to distinct populations or groups based on the chemical 
composition of their otoliths at a given time, often in an effort to discriminate stocks (Campana et al. 1999, Rooker et al. 2003); (2) analyses of movement, often between marine and freshwaters in diadromous species (e.g. Rieman et al. 1994, Tzeng \& Tsai 1994, Secor et al. 2001), or migrations among habitats or regions over different life history stages.

Because they require information from specific times during the life of an individual fish, studies of individual movement require precise sampling of the otolith and usually employ laser ablation inductively coupled plasma mass spectrometry (LA-ICPMS, Campana 1999). Many of these studies use the same general approach. They first demonstrate that differences in otolith chemistry exist among sites, using a reference collection of individuals from the pre-migration life history stage, such as juveniles that use estuaries before moving to open coasts as adults (Milton et al. 1997, Thorrold et al. 1998, Gillanders 2002). This reference collection serves as a training dataset to subsequently assign adults (collected after an appropriate time interval determined by the life history of the species) to a pre-migration site of origin based on similarities between the chemical signatures of the portions of their otoliths deposited during the juvenile life stage and the training dataset. These data can provide information about movement patterns such as rates of natal homing in migratory species (Thorrold et al. 2001) or the relative contribution of various nursery estuaries to adult populations (Gillanders 2002).

Studies of species that use estuaries as juvenile habitat benefit from the fact that chemical differences among estuaries are often large and individuals spend considerable time in them (Thorrold et al. 1998). A relatively large amount of otolith material that is distinctive in its chemical composition is deposited during the juvenile stage, greatly facilitating analyses. However, most marine fishes spend their entire lives in fully marine environments, with a short larval phase and a long adult phase. In many of these species, exchange among populations may occur exclusively during the larval phase. Because the larval phase may last weeks or months and mortality during this phase is high, it has been all but impossible to measure rates of larval exchange among populations (but see Jones et al. 1999, 2005 for discussions of larval retention). However, this information remains critical to understanding marine population dynamics and improving management of marine resources (see Caley et al. 1996, Warner \& Cowen 2002 and references therein). Because of its importance, there has been increasing interest in using methods in otolith chemistry to address questions of larval exchange.

Using otolith chemistry to track dispersing larvae requires the same types of information needed to track movements of adults or juveniles: (1) a training dataset of otolith chemical composition from potential source sites before dispersal occurs (i.e. an atlas of chemical signatures from natal sites), and (2) the means to measure the chemical composition of that portion of the otolith after dispersal. In the case of dispersing larvae, the pre-migration portion of the otolith is comprised of otolith material deposited at the natal site; this material forms the core of the otolith as it grows and it is this portion of the otolith that will provide information about natal site in post-larval individuals.

Even in species that brood eggs, the pre-pelagic larvae spend only days to a few weeks at their natal sites before entering the pelagic phase of development. Thus, while otoliths may begin development at the natal site, the portion of the otolith that contains the natal signature is often quite small (usually $<50 \mu \mathrm{m}$ in diameter; Ruttenberg et al. 2005a, Warner et al. 2005). To complicate matters further, emerging research has shown that chemical signatures from natal otoliths may not reflect the water chemistry at that site around the time of sampling (Warner et al. 2005) and that levels of many elements are elevated in cores relative to noncore regions of the otolith (Brophy et al. 2004, Ruttenberg et al. 2005a). These new findings suggest that it may be difficult or impossible to use proxies, such as water samples or non-core regions of otoliths from other individuals at the sites of interest, to create the atlas of chemical signatures. Instead, it appears that collections of natal otoliths themselves from potential source sites are needed to provide this information.

An appropriate study system to examine variation in natal otolith chemistry should have a number of characteristics. Sites should span at least the expected dispersal distance of the study species to provide some useful information about exchange, and otolith chemistry should vary across a similar spatial extent. Collections of pre-pelagic otoliths (ideally from benthic or other type of brooded eggs) should be made over as short a time span as possible, because temporal variation in otolith chemistry across sites may confound spatial patterns (Milton et al. 1997, Gillanders \& Kingsford 2000, Swearer et al. 2003). Finally, collections of recruits should be made after natal collections, with a time interval approximately equal to the length of the pelagic larval stage of the study species.

In the first published studies of the chemistry of natal otoliths and statoliths (analogous structures in mollusks), Warner et al. (2005) and Zacherl (2005) found spatial variation in natal signatures of a fish and a snail, focusing in both cases on a single spatial scale. In this paper, we present data on the chemistry of natal otoliths of a damselfish (Stegastes beebei) from the Galápagos Islands and examine patterns of variation at multiple spatial scales. We found no usable variation at 
the largest scale $(\sim 100 \mathrm{~km})$, but found significant variation at smaller scales (10s of $\mathrm{km})$. We compare these natal otolith chemical signatures to signatures of the cores of newly recruited individuals and find that they differ significantly. These results highlight the importance of matching the study scale with the scale of chemical variation and the dispersal scale of the study organism when using otolith chemistry to track larval dispersal.

\section{MATERIALS AND METHODS}

Study system, study species, and collections. We chose the Galápagos Islands as our study system because strong gradients in temperature (and presumably water chemistry) exist across the archipelago. The islands sit on the equator $1000 \mathrm{~km}$ west of the South American mainland at the confluence of 3 main ocean currents. These currents create a number of hydrogeographic regions within the islands that vary in temperature and productivity (see Glynn \& Wellington 1983 for more details). Regions are separated by $<150 \mathrm{~km}$, but regional differences in sea surface temperature (SST) may exceed $5^{\circ} \mathrm{C}$ and productivity may vary 10fold among regions (Wellington et al. 2001, Palacios 2002, Ruttenberg et al. 2005b). Over the scale of the entire archipelago, we divide the islands into 3 regions based on the largest differences in SST: (1) North, where temperatures are warmest, (2) West, where temperatures are coldest, and (3) Central/South (hereafter referred to as Central), where temperatures were generally intermediate between the North and West (Fig. 1).

We selected Stegastes beebei, the white-tailed damselfish, as our study species, because they are abundant on shallow reefs throughout the archipelago and they lay and guard benthic eggs in nests. We collected egg masses from 149 clutches from all regions of the islands on a series of cruises from 21 April to 24 May, 2002. Of these 61 were late-stage clutches that yielded otoliths in sufficient quantity for analysis (Table 1). We made collections of $>200$ recruits using hand nets on similar cruises from 6 to 26 June, 2002. All specimens were stored in glass vials in $95 \%$ EtOH after capture.

Otolith extraction, preparation and analysis. We used previously published protocols for extracting otoliths from egg masses (Warner et al. 2005, Zacherl 2005). Natal otoliths were extracted in batches by clutch by digesting the organic matter in $15 \%$ semiconductor grade $\mathrm{H}_{2} \mathrm{O}_{2}$ buffered with $0.05 \mathrm{~N}$ Suprapure $\mathrm{NaOH}$ (hereafter referred to as 'buffered $\mathrm{H}_{2} \mathrm{O}_{2}$ ') for $30 \mathrm{~min}$. We then sequentially transferred the otoliths through 4 rinsing steps using ultra-pure water $(\mathrm{N}$ pure, resistivity $>18.1 \mathrm{M} \Omega \mathrm{cm}$ ), each in a separate,

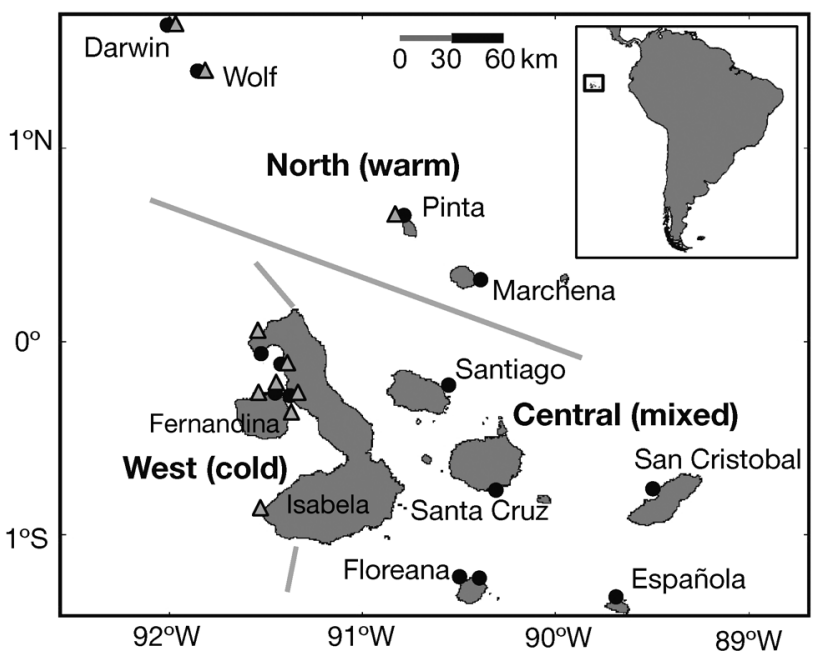

Fig. 1. Map of Galápagos showing collection sites. Black circles: sites where broods that yielded otoliths were collected; gray triangles: sites where recruits were collected and subsequently analyzed. Egg collection sites in West regionnorthernmost: Isabela North; middle: Isabela Mid; southern 2 sites: Canal Bolivar

clean beaker and pipetted the otoliths onto a clean, acid-washed $20 \times 20 \mathrm{~mm}$ plastic slide. When the excess water evaporated, we mounted otoliths using doublesided Scotch ${ }^{\mathrm{TM}}$ tape. All extractions occurred in a clean lab with HEPA-filter class 100 laminar flow hoods, and all glassware was acid washed prior to use.

Procedures for preparing recruit otoliths followed those of Ruttenberg et al. (2005a). Only 87 of the recruits we collected were $<16 \mathrm{~mm}$ standard length (SL), and thus likely less than a few weeks old (B. I. Ruttenberg unpubl. data). Because these samples are time-consuming to prepare and run, we selected a subset (30) of these samples for analysis, and included samples only from the North and West. One sagittal otolith was mounted sulcus side up on a clean plastic slide in low-viscosity resin (Buehler Epo-Thin epoxy resin). We polished otoliths to between 5 and $25 \mu \mathrm{m}$ above the core using a lapping wheel and 9 and $3 \mu \mathrm{m}$

Table 1. Stegastes beebei. Summary of collections of clutches and recruits $(<16 \mathrm{~mm})$, by region. anal. = analyzed, coll. = collected, NA = not applicable

\begin{tabular}{|c|c|c|c|c|c|c|}
\hline \multirow{2}{*}{ Region } & \multicolumn{3}{|c|}{ Clutches- } & \multirow[b]{2}{*}{$\begin{array}{l}\text { No. } \\
\text { sites }\end{array}$} & \multicolumn{2}{|c|}{ Recruits } \\
\hline & $\begin{array}{c}\text { No. } \\
\text { islands }\end{array}$ & $\begin{array}{l}\text { No. } \\
\text { coll. }\end{array}$ & $\begin{array}{l}\text { No. } \\
\text { anal. }\end{array}$ & & $\begin{array}{l}\text { No. } \\
\text { coll. }\end{array}$ & $\begin{array}{l}\text { No. } \\
\text { anal. }\end{array}$ \\
\hline North & 3 & 52 & 14 & 3 & 34 & 14 \\
\hline Central & 5 & 59 & 29 & NA & NA & NA \\
\hline West & $3^{\mathrm{a}}$ & 38 & 18 & 7 & 41 & 15 \\
\hline Total & 11 & 149 & 61 & 10 & 75 & 29 \\
\hline
\end{tabular}


Table 2. Estimates of precision and limits of detection. Note that for limits of detection, values for $\mathrm{Mg}: \mathrm{Ca}$ and $\mathrm{Sr}: \mathrm{Ca}$ are given in $\mathrm{mmol} \mathrm{mol}^{-1}$, and $\mathrm{Mn}: \mathrm{Ca}, \mathrm{Ba}: \mathrm{Ca}$, and $\mathrm{Pb}: \mathrm{Ca}$ are given in $\mu \mathrm{mol} \mathrm{mol}{ }^{-1}$. Values for \%RSD (\% relative standard deviation) are dimensionless. NIST: National Institute of Standards and Technology; NA: not applicable

\begin{tabular}{|c|c|c|c|c|}
\hline Element & $\begin{array}{c}\text { NIST \%RSD, } \\
\text { low } \\
\text { resolution }\end{array}$ & $\begin{array}{l}\text { NIST \%RSD, } \\
\text { medium } \\
\text { resolution }\end{array}$ & $\begin{array}{l}\text { Limits of } \\
\text { detection, } \\
\text { low } \\
\text { resolution }\end{array}$ & $\begin{array}{c}\text { Limits of } \\
\text { detection, } \\
\text { medium } \\
\text { resolution }\end{array}$ \\
\hline $\mathrm{Mg}: \mathrm{Ca}$ & NA & 20 & NA & 0.037 \\
\hline $\mathrm{Mn}: \mathrm{Ca}$ & NA & 13 & NA & 1.10 \\
\hline $\mathrm{Sr}: \mathrm{Ca}$ & 26 & 15 & 0.061 & 0.017 \\
\hline $\mathrm{Ba}: \mathrm{Ca}$ & 8 & 14 & 0.15 & 0.35 \\
\hline $\mathrm{Pb}: \mathrm{Ca}$ & 16 & 22 & 0.18 & NA \\
\hline
\end{tabular}

Table 3. Cutoff values for data filter. Note that for maximum value, values of $\mathrm{Mg}: \mathrm{Ca}$ and $\mathrm{Sr}: \mathrm{Ca}$ are given in $\mathrm{mmol} \mathrm{mol}^{-1}$,

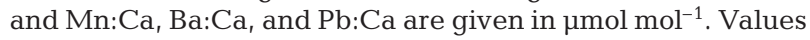
for maximum \%RSD are dimensionless

\begin{tabular}{|lcc|}
\hline Element & Maximum value & Maximum \%RSD \\
\hline $\mathrm{Mg}: \mathrm{Ca}$ & 3 & 100 \\
$\mathrm{Mn}: \mathrm{Ca}$ & 1000 & 75 \\
$\mathrm{Sr}: \mathrm{Ca}$ & 5 & 50 \\
$\mathrm{Ba}: \mathrm{Ca}$ & 36 & 75 \\
$\mathrm{~Pb}: \mathrm{Ca}$ & 2 & 100 \\
\end{tabular}

ments ${ }^{48} \mathrm{Ca},{ }^{86} \mathrm{Sr},{ }^{138} \mathrm{Ba}$ and ${ }^{208} \mathrm{~Pb}$ and 12 otoliths in medium resolution $(\mathrm{R}=3000$, hereafter referred to as $\mathrm{MR})$ for ${ }^{24} \mathrm{Mg},{ }^{48} \mathrm{Ca}$, and ${ }^{55} \mathrm{Mn}$. Due to their small size $(<30 \mu \mathrm{m}$ in diameter), each natal otolith was completely consumed during analysis. For the recruit otoliths, we sought to analyze only material associated with the core. Previous work has found that the cores of otoliths contain elevated levels of $\mathrm{Mn}$ and that this elevated Mn may be used as a proxy to identify material associated with the core (Brophy et al. 2004, Ruttenberg et al. 2005a). To isolate material associated with the core, we ablated a series of small discrete pits consisting of 8 laser pulses in a vertical transect over the region of the otolith that was visually determined to be the core (Ruttenberg et al. 2005a), pre-ablating the area over the core with 2 laser pulses to remove any surface contamination. Each pit consisted of subsequently deeper material from within the same crater, and we acquired data independently for each pit using only 8 laser pulses. After analysis, we identified the pit that contained the core using a spike in Mn as a proxy (Ruttenberg et al. 2005a). However, since Mn is only quantifiable in $\mathrm{MR}$, all isotopes for analyses of recruit cores were conducted in MR. Values of $\mathrm{Pb}$ in recruit cores were consistently below MR detection limits (usually $>2 \mu \mathrm{mol} \mathrm{mol}{ }^{-1}$ in $\mathrm{MR}$ vs. $\sim 0.2 \mu \mathrm{mol} \mathrm{mol}{ }^{-1}$ in LR), so we excluded this element from further analyses of recruits. To maintain instrument precision, we ana-
$3 \mathrm{M}^{\circledR}$ diamond polishing film. After polishing, otoliths were rinsed in $\mathrm{N}$ pure, soaked in buffered $\mathrm{H}_{2} \mathrm{O}_{2}$ in acidleached trays for $1 \mathrm{~h}$, rinsed again with $\mathrm{N}$-pure, sonicated 3 times for $5 \mathrm{~min}$ in $\mathrm{N}$-pure and rinsed a final time with $\mathrm{N}$ pure. Samples were then dried in class 100 laminar flow hoods and stored in covered plastic trays until analysis.

All samples were analyzed with a Finnegan MAT Element 2-sector field ICPMS using a VG-UV microprobe $\mathrm{Nd}$ :YAG $266 \mu \mathrm{m}$ laser ablation system, with the laser pulsed at $3 \mathrm{~Hz}$ (see Warner et al. 2005, Ruttenberg et al. 2005a for more details). We normalized each analyte to $\mathrm{Ca}$ by calculating the ratio of metal to $\mathrm{Ca}$, mass-bias corrected using calibration standards with known analyte to Ca ratios (Ruttenberg et al. 2005a, Warner et al. 2005). Natal otoliths were analyzed by clutch; we analyzed 12 otoliths per clutch in low resolution $(\mathrm{R}=300$, hereafter referred to as LR) for the ele-
Table 4. Stegastes beebei. Results of univariate ANOVA for natal otoliths. For all elements, the model included Region as a fixed factor, and Island nested within Region and Clutch nested within Island and Region as random factors. NS: nonsignificant

\begin{tabular}{|c|c|c|c|c|c|}
\hline Element & Source & df & MS & $F$ & $\begin{array}{l}\text { Bonferroni } \\
\text { corrected } p\end{array}$ \\
\hline $\mathrm{Mg}$ & $\begin{array}{l}\text { Region } \\
\text { Island (Region) } \\
\text { Clutch (Region, Island) } \\
\text { Error }\end{array}$ & $\begin{array}{r}2 \\
7 \\
44 \\
451\end{array}$ & $\begin{array}{l}2.56 \\
5.05 \\
1.36 \\
0.25\end{array}$ & $\begin{array}{l}0.60 \\
4.12 \\
5.42\end{array}$ & $\begin{array}{c}\text { NS } \\
0.007 \\
<0.0001\end{array}$ \\
\hline Mn & $\begin{array}{l}\text { Region } \\
\text { Island (Region) } \\
\text { Clutch (Region, Island) } \\
\text { Error }\end{array}$ & $\begin{array}{r}2 \\
7 \\
47 \\
578\end{array}$ & $\begin{array}{l}2.00 \\
1.85 \\
0.96 \\
0.39\end{array}$ & $\begin{array}{l}1.10 \\
1.95 \\
2.46\end{array}$ & $\begin{array}{c}\text { NS } \\
\text { NS } \\
<0.0001\end{array}$ \\
\hline $\mathrm{Sr}$ & $\begin{array}{l}\text { Region } \\
\text { Island (Region) } \\
\text { Clutch (Region, Island) } \\
\text { Error }\end{array}$ & $\begin{array}{r}2 \\
7 \\
47 \\
611\end{array}$ & $\begin{array}{l}0.31 \\
1.45 \\
0.60 \\
0.19\end{array}$ & $\begin{array}{l}0.22 \\
2.46 \\
3.22\end{array}$ & $\begin{array}{c}\text { NS } \\
\text { NS } \\
<0.0001\end{array}$ \\
\hline $\mathrm{Ba}$ & $\begin{array}{l}\text { Region } \\
\text { Island (Region) } \\
\text { Clutch (Region, Island) } \\
\text { Error }\end{array}$ & $\begin{array}{r}2 \\
7 \\
47 \\
612\end{array}$ & $\begin{array}{r}1.10 \\
17.88 \\
2.83 \\
0.15\end{array}$ & $\begin{array}{r}0.06 \\
6.58 \\
19.50\end{array}$ & $\begin{array}{c}\text { NS } \\
0.0001 \\
<0.0001\end{array}$ \\
\hline $\mathrm{Pb}$ & $\begin{array}{l}\text { Region } \\
\text { Island (Region) } \\
\text { Clutch (Region, Island) } \\
\text { Error }\end{array}$ & $\begin{array}{r}2 \\
7 \\
46 \\
419\end{array}$ & $\begin{array}{l}2.18 \\
1.61 \\
1.72 \\
0.17\end{array}$ & $\begin{array}{r}1.54 \\
1.03 \\
10.02\end{array}$ & $\begin{array}{c}\text { NS } \\
\text { NS } \\
<0.0001\end{array}$ \\
\hline
\end{tabular}


lyzed solid glass standard material from the National Institute of Standards and Technology (NIST 612) along with samples; estimates of precision as coefficients of variation among replicate analyses of the NIST standards are listed in Table 2.

Data analysis. The small amount of material ablated from natal otoliths occasionally resulted in low signal stability and high percent relative standard deviation (\%RSD) of elemental ratios for a given otolith. Because data associated with high \%RSDs are more uncertain, we applied a filter that eliminated individual natal otoliths with high \%RSDs. Because some contamination of natal otoliths is possible, we also filtered out data points whose absolute values exceeded a prescribed maximum value for a given element, usually determined as $\sim 2 \times$ the maximum value observed in cores of recruits (Table 3 ). These filters removed less than $6 \%$ of the data for each element, with the exception of $\mathrm{Mg}$, for which $38 \%$ of the data exceeded the maximum. Therefore, Mg data are shown for comparison only but were not used in multivariate analyses.

For natal otoliths, we used nested ANOVAs to examine univariate differences among regions, islands within regions, and clutches within islands, and nested MANOVAs to examine these patterns in multielemental signatures, using individual otoliths as replicates. Islands that included only 1 or 2 clutches were excluded from analyses. Since the West only includes 2 large islands, we divided it into 3 areas (which are coded as 'islands' in analyses): Isabela North, Isabela Mid, and Canal Bolivar (Fig. 1). Finally, we used discriminant function analyses (DFA) to examine patterns of chemical signature variation in multivariate space. Because data for different elements were analyzed in different resolutions (and therefore were from different otoliths), we ran 2 sets of DFAs: (1) using data from individual otoliths with the LR elements only ( $\mathrm{Sr}, \mathrm{Ba}$, and $\mathrm{Pb}$ ) and (2) using clutch means using $\mathrm{Sr}, \mathrm{Ba}, \mathrm{Pb}$, and $\mathrm{Mn}$. We examined patterns across regions and among islands within each region. We used a randomization test to determine if the jackknife (i.e. leave 1 out) reclassification success rate was significantly different from random (White \& Ruttenberg in press). This test takes the actual data and iteratively randomizes the grouping variable with respect to the response variables to determine the probability of obtaining the observed reclassification rate due to chance alone.

For cores of recruits, we used ANOVA to examine univariate differences among regions. To determine if the otolith cores in fact resemble the natal otoliths from which they supposedly arose, we used the natal otolith data as a training dataset for the DFA to classify cores or recruits. Data for both natal otoliths and recruit cores were log or square root transformed when necessary to improve normality. All analyses were con-
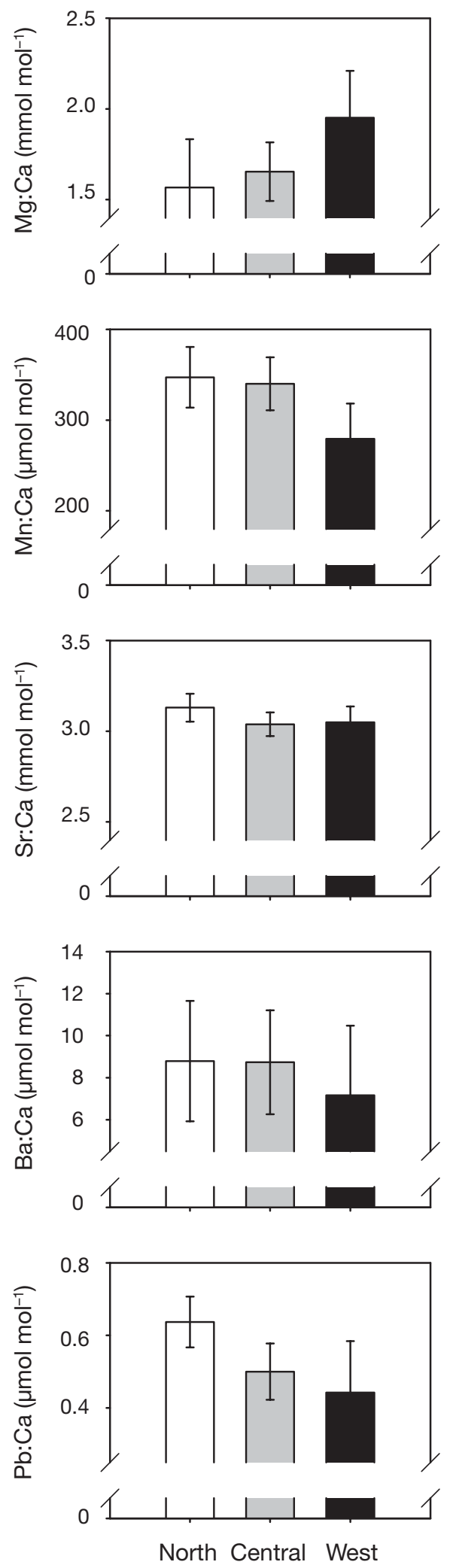

Fig. 2. Stegastes beebei. Ratios of elemental concentrations in natal otoliths grouped by region. Differences among regions were non-significant for all elements. Error bars are $\pm 1 \mathrm{SE}$ 
ducted on transformed data, and all p-values were Bonferroni-corrected after analyses for multiple comparisions (e.g. p $=0.01$ for a test run 5 times would be reported as 0.05). We followed statistical procedures of Sokol \& Rohlf (1995).

\section{RESULTS}

\section{Natal otoliths}

The primary goals of this study were to evaluate methods for measuring the chemical signatures in natal otoliths and to examine patterns of variation in those signatures across regions, islands, and clutches. Univariate ANOVAs revealed significant variation among clutches within islands for all 5 elements, and significant variation among islands within regions for $\mathrm{Mg}$ and $\mathrm{Ba}$. None of the 5 elements varied significantly among regions (Table 4, Fig. 2). Results from nested MANOVAs were qualitatively similar to those from univariate tests. A nested MANOVA using the LR elements $(\mathrm{Sr}, \mathrm{Ba}, \mathrm{Pb})$ found no significant variation at the regional level, but highly significant variation among islands and among clutches (Table 5).

We used DFA to characterize multivariate elemental profiles. Analyses using data from individual otoliths (using the LR elements $\mathrm{Sr}, \mathrm{Ba}, \mathrm{Pb}$ only) showed that
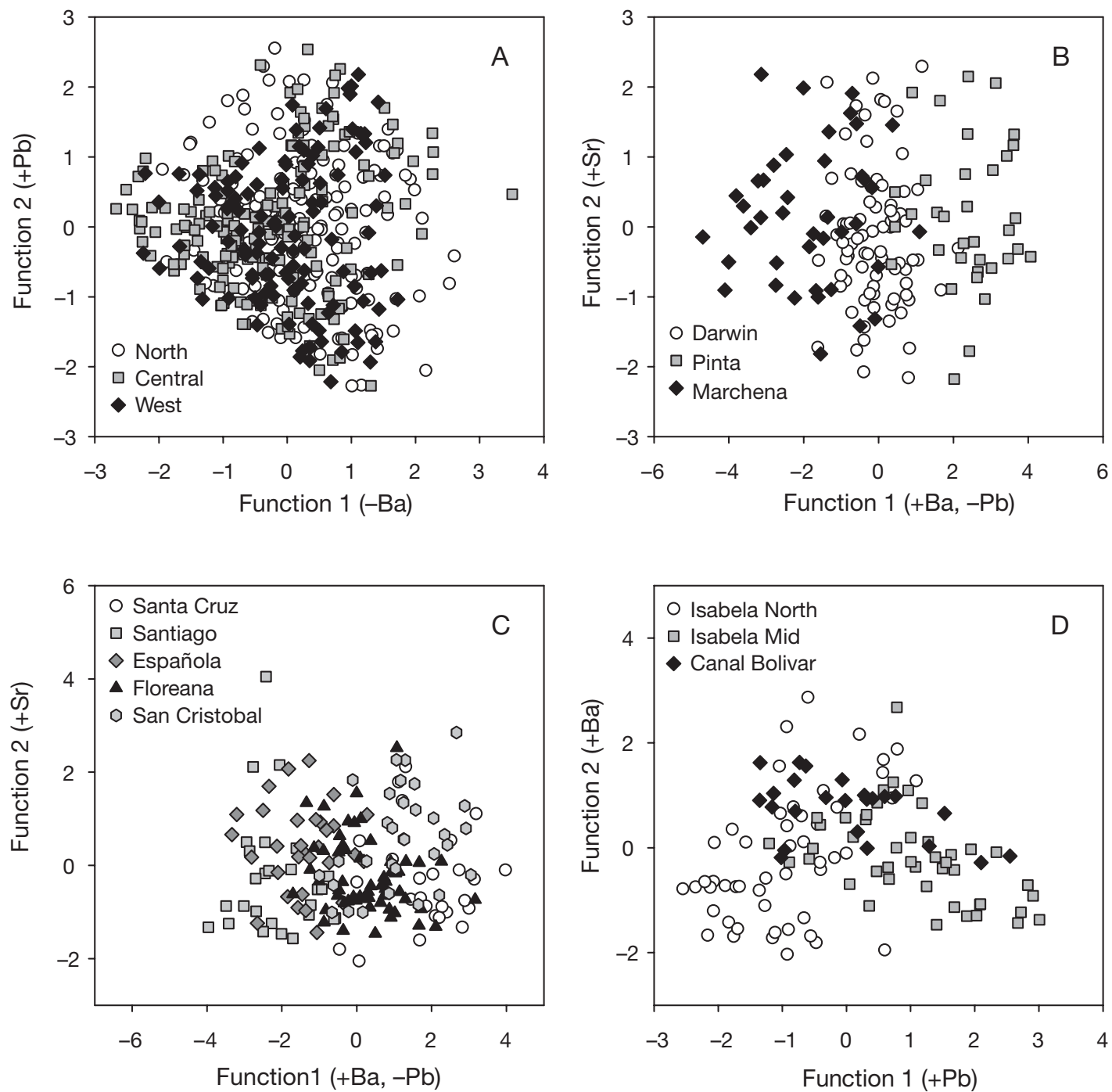

Fig. 3. Stegastes beebei. Discriminant Function Analysis of natal otoliths. Each point represents a single otolith. All plots were generated using the low-resolution elements only ( $\mathrm{Sr}, \mathrm{Ba}, \mathrm{Pb})$. (A) By region, using all data. (B-D) Otoliths classified to island, using only samples from the (B) North, (C) Central and (D) West. Jackknife values are: 43.5, 82.7, 57.2 and $66.4 \%$ for (A-D), respectively. See Table 6 for discriminant function loadings 
Table 5. Stegastes beebei. Results of nested MANOVAs for natal otoliths. The model included Region as a fixed factor, and Island nested within Region and Clutch nested within Island and Region as random factors. NS: non-significant

\begin{tabular}{|lcccc|}
\hline Level & $\begin{array}{c}\text { Pillai's } \\
\text { trace }\end{array}$ & $F$ & $\begin{array}{c}\mathrm{df} \\
\text { (num, } \\
\text { den) }\end{array}$ & $\begin{array}{c}\text { Bonferroni } \\
\text { corrected } \\
\mathrm{p}\end{array}$ \\
\hline Region & 0.27 & 0.36 & 6,14 & $\mathrm{NS}$ \\
Island (Region) & 1.21 & 3.46 & 24,123 & $<0.0001$ \\
Clutch (Island, Region) & 1.22 & 6.32 & 123,1140 & $<0.0001$ \\
\hline
\end{tabular}

elemental signatures had little power to discriminate regions. The cross-validated (jackknife) reclassification success rate was $43.5 \%$, which, while significantly different from random ( $p<0.001$, White \& Ruttenberg in press), still provides little discriminatory power (Fig. 3A \& Table 6).

However, within-region analyses, grouping otoliths by island, resulted in much higher jackknife reclassification success rates using the LR elements $(82.7 \%$ in the North with 3 islands, $57.2 \%$ in the Central with 5 islands, and $66.4 \%$ in the West with 3 areas), all of which were significantly greater than random ( $p<$ 0.001; Fig. 3B-D). Analyses of clutch means using all elements yielded qualitatively similar results for jackknife reclassification success rates (to region: 49.1\%; within region to island, North: $73.3 \%$, Central: $52.0 \%$, West: $84.6 \%$; Fig. 4). The reclassification success rate to region was not significantly different from random ( $p>0.10)$, while the within-region reclassification rates were marginally significant or better (North: $p=0.07$, Central: $p=0.03$, West: $p=0.01$ ). Because $\mathrm{Pb}$ was undetectable in recruit cores (see 'Materials and methods'), we ran additional DFAs using clutch means for $\mathrm{Sr}, \mathrm{Ba}$, and $\mathrm{Mn}$, classifying otoliths to region or to island within region, with similar results (see below).

\section{Recruit otoliths}

We included samples of recruit cores only from the North and West to maintain adequate sample size in our analyses. Univariate ANOVAs showed no significant variation for any element in the cores of recruits, either between regions or among islands within regions.

To use otolith chemistry to track larval dispersal, elemental signatures of otolith cores of recruits spawned at a given site should match those of natal otoliths produced at that site. At the very least, there should be strong overlap between elemental levels in an atlas generated from natal otoliths and cores of recruits that were likely spawned at some of the same sites. The range of values for natal otoliths encompassed the range of values for recruit otoliths for all elements. However, mean values in natal otoliths were significantly greater in natal otoliths than recruit cores (Fig. 5), and many of the recruit cores fell outside of the DFA space created using $\mathrm{Sr}, \mathrm{Ba}$ and $\mathrm{Mn}$ from clutch means of natal otoliths, regardless of whether we use data from all regions, or restrict analyses to individual regions (Fig. 6). Computing the bivariate probabilities from the univariate cumulative distribution functions for each discriminant function revealed that only 31,79 or $20 \%$ of the recruits fell into the $95 \%$ confidence space of the natal otoliths, depending on which dataset was used (either All regions, North only or West only, respectively).

Table 6. Stegastes beebei. Weights for the discriminant functions (DF), by element. Each set of values corresponds to a specific analysis for a specific figure. (Fig. reference): source in the present study

\begin{tabular}{|c|c|c|c|}
\hline Analysis (Fig. reference) & Element & DF 1 & DF 2 \\
\hline By Region: all otoliths (3A) & $\begin{array}{l}\mathrm{Sr} \\
\mathrm{Ba} \\
\mathrm{Pb}\end{array}$ & $\begin{array}{r}0.46 \\
-0.88 \\
0.66\end{array}$ & $\begin{array}{r}-0.31 \\
0.51 \\
0.78\end{array}$ \\
\hline North only: all otoliths (3B) & $\begin{array}{l}\mathrm{Sr} \\
\mathrm{Ba} \\
\mathrm{Pb}\end{array}$ & $\begin{array}{r}0.01 \\
1.10 \\
-0.34\end{array}$ & $\begin{array}{r}1.04 \\
-0.21 \\
-0.13\end{array}$ \\
\hline Central only: all otoliths (3C) & $\begin{array}{l}\mathrm{Sr} \\
\mathrm{Ba} \\
\mathrm{Pb}\end{array}$ & $\begin{array}{r}0.12 \\
1.09 \\
-0.67\end{array}$ & $\begin{array}{l}0.69 \\
0.03 \\
0.61\end{array}$ \\
\hline West only: all otoliths (3D) & $\begin{array}{l}\mathrm{Sr} \\
\mathrm{Ba} \\
\mathrm{Pb}\end{array}$ & $\begin{array}{r}-0.23 \\
0.49 \\
0.84\end{array}$ & $\begin{array}{r}-0.34 \\
1.00 \\
-0.56\end{array}$ \\
\hline By Region: Clutch means (4A) & $\begin{array}{l}\mathrm{Sr} \\
\mathrm{Ba} \\
\mathrm{Pb} \\
\mathrm{Mn}\end{array}$ & $\begin{array}{r}-0.05 \\
0.95 \\
-0.46 \\
-0.24\end{array}$ & $\begin{array}{r}-0.40 \\
0.11 \\
0.14 \\
0.91\end{array}$ \\
\hline North only: Clutch means (4B) & $\begin{array}{l}\mathrm{Sr} \\
\mathrm{Ba} \\
\mathrm{Pb} \\
\mathrm{Mn}\end{array}$ & $\begin{array}{r}0.23 \\
1.12 \\
-0.58 \\
0.17\end{array}$ & $\begin{array}{r}0.96 \\
-0.25 \\
0.21 \\
-0.73\end{array}$ \\
\hline Central only: Clutch means (4C) & $\begin{array}{c}\mathrm{Sr} \\
\mathrm{Ba} \\
\mathrm{Pb} \\
\mathrm{Mn}\end{array}$ & $\begin{array}{r}0.53 \\
1.16 \\
-0.97 \\
0.37\end{array}$ & $\begin{array}{r}0.14 \\
-0.30 \\
-0.39 \\
0.80\end{array}$ \\
\hline West only: Clutch means (4D) & $\begin{array}{c}\mathrm{Sr} \\
\mathrm{Ba} \\
\mathrm{Pb} \\
\mathrm{Mn}\end{array}$ & $\begin{array}{r}0.66 \\
-2.53 \\
1.30 \\
1.52\end{array}$ & $\begin{array}{r}0.23 \\
0.21 \\
0.86 \\
-0.35\end{array}$ \\
\hline By Region \& Recruits (6A) & $\begin{array}{c}\mathrm{Sr} \\
\mathrm{Ba} \\
\mathrm{Mn}\end{array}$ & $\begin{array}{r}-0.20 \\
1.02 \\
0.02\end{array}$ & $\begin{array}{r}-0.35 \\
-0.23 \\
0.96\end{array}$ \\
\hline North only \& Recruits (6B) & $\begin{array}{c}\mathrm{Sr} \\
\mathrm{Ba} \\
\mathrm{Mn}\end{array}$ & $\begin{array}{r}0.19 \\
0.95 \\
-0.01\end{array}$ & $\begin{array}{r}0.98 \\
-0.24 \\
-0.68\end{array}$ \\
\hline West only \& Recruits (6C) & $\begin{array}{c}\mathrm{Sr} \\
\mathrm{Ba} \\
\mathrm{Mn}\end{array}$ & $\begin{array}{r}0.34 \\
-1.60 \\
1.27\end{array}$ & $\begin{array}{r}0.77 \\
-0.01 \\
0.49\end{array}$ \\
\hline
\end{tabular}



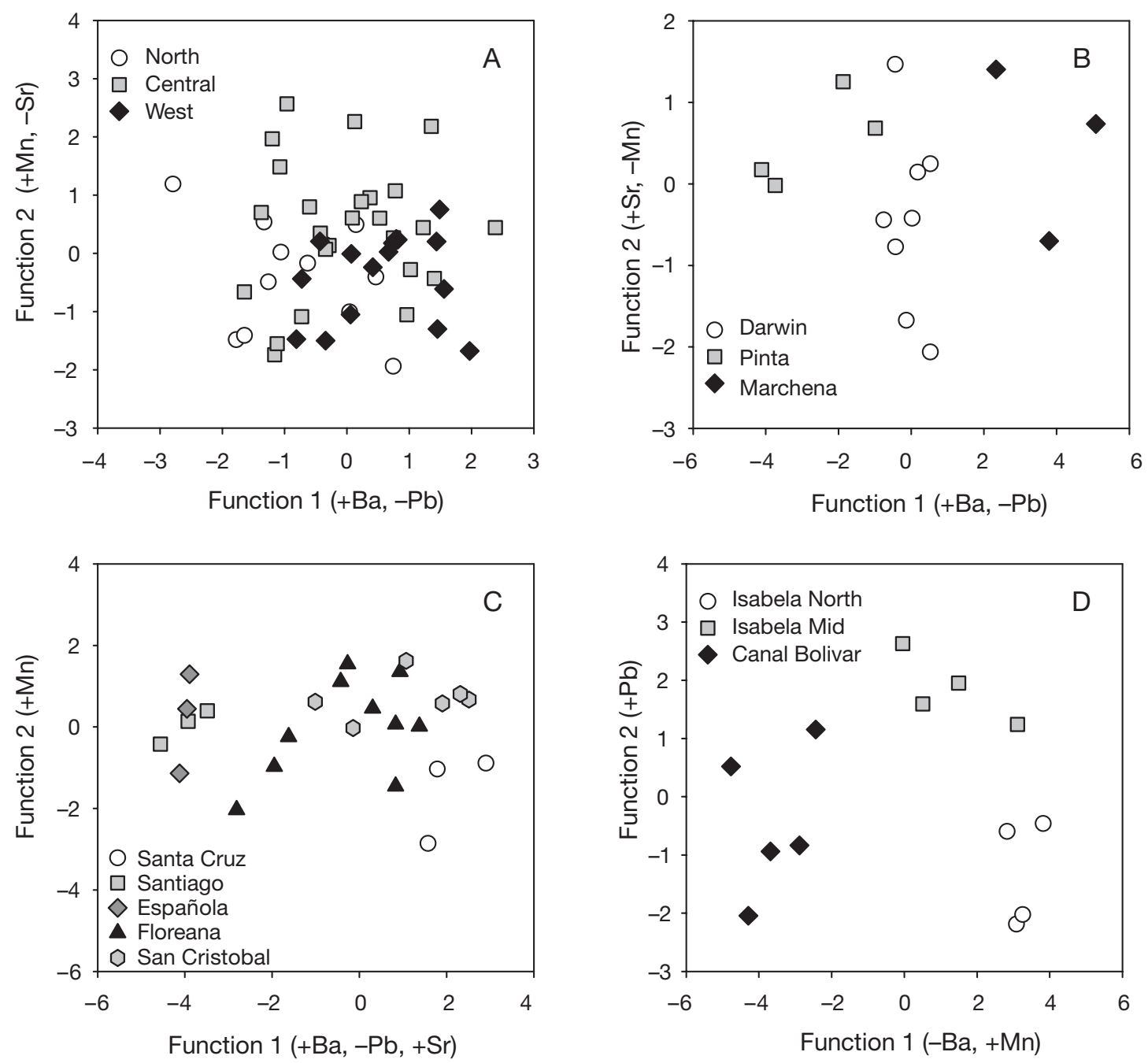

Fig. 4. Stegastes beebei. Discriminant Function Analysis of natal otoliths, using clutch means (elements $\mathrm{Mn}, \mathrm{Sr}, \mathrm{Ba}, \mathrm{Pb}$ ). Each point represents the mean of a single clutch. (A) By region, using all clutches. (B-D) Clutches classified to island, using only clutches from (B) North, (C) Central, and (D) West. Jackknife values are: 49.1, 73.3, 52.0 and 84.6\% for (A-D), respectively. See Table 6 for discriminant function loadings

\section{DISCUSSION}

Otolith chemistry can be used to investigate larval dispersal by examining the chemical composition of natal otoliths over different spatial scales. We expected the strong regional differences in temperature and productivity in Galápagos to result in regional differences in natal otolith chemistry, because differences in temperature often result in differences in the chemical composition of otoliths and statoliths (Bath et al. 2000, Zacherl et al. 2003, Martin \& Thorrold 2005). However, while there were no differences in natal otolith chemistry among regions for any element, a few elements varied significantly among islands within regions, and all elements showed significant variation among clutches within sites (Table 4).
Multivariate analyses revealed that some spatial structure exists in the natal otolith data. Using either individual otoliths or clutch means, DFAs performed poorly in reclassifying otoliths to region, suggesting that there is little usable variation in the chemical signatures of natal otoliths across the entire archipelago (Figs. 3A \& 4A). However, we found evidence of more spatial structure in multi-element signatures within regions (classifying otoliths to island within each region). Interestingly, the patterns in multivariate space do not match the actual geographical location of islands (i.e. areas intermediate in DFA scores are not physically located between areas with more extreme score; Figs. 1, $3 \& 4$ ). Still, DFAs successfully reclassified otoliths to island with fairly high success rates in all regions (Figs. 3 \& 4). Regions are separated by 
$\sim 100 \mathrm{~km}$, but islands within regions are often separated by no more than 20 to $30 \mathrm{~km}$ (Fig. 1). These results imply that otolith chemical signatures vary consistently over moderate spatial scales $(<50 \mathrm{~km})$, but not over larger regional scales in Galápagos. If we can determine that dispersal scales match the scale of chemical variation, it may be possible to use this variation to assign recruits to natal sources.

Other studies have found variation in the chemical signature of biogenic carbonates over small scales, such as among sites along a small stretch of coastline or within estuaries, but these studies also detected variation over larger scales (e.g. Gillanders \& Kingsford 2000, Becker et al. 2005). Our results differ in that usable variation exists over smaller spatial scales but not over larger ones. Such patterns of variation could be in part the result of the unique oceanography of Galápagos. It is possible that regional temperature variation across the Galápagos (up to $8^{\circ} \mathrm{C}$ ) alone is not enough to affect the chemical composition of natal otoliths significantly. Temporal variability in temperature at a given site may be quite high (Witman \& Smith 2003, B. I. Ruttenberg unpubl. data), and small-scale spatial variability in temperature may also be common. While upwelling is more persistent in the West, is occurs throughout the islands and may be extremely localized. If upwelling (i.e. changes in temperature) influences natal otolith chemistry, variation in upwelling intensity among the sites we selected within each region could create sufficient differences in chemical signatures to distinguish sites or islands within regions. Furthermore, upwelling intensity among sites may be uncorrelated spatially (J. Witman unpubl. data), which could also explain the mismatch between the location of islands in multivariate space and their position geographically (Figs. 1, $3 \& 4$ ). The presence of high and low upwelling sites in each region would reduce variance among regions. Unfortunately, we only have temperature records from a few of our sites, so we are unable to test this idea.

We also found high among-clutch variation for all elements. It is possible that this variation may be the result of maternal effects on the chemical composition of natal otoliths or the result of some contamination during processing. While the impact of maternal provisioning on the chemistry of natal otoliths is unknown, recent research suggests that these maternal effects on otolith chemistry may be stronger than once expected. Thorrold et al. (2006) found that rare isotopes of $\mathrm{Ba}$ injected into female fish altered the natural isotopic ratios of those elements in the natal otoliths of their offspring. These findings strongly suggest that the source of at least some elements in natal otoliths is yolk. Warner et al. (2005) and Zacherl (2005) also found significant among-clutch variation, and suggested that
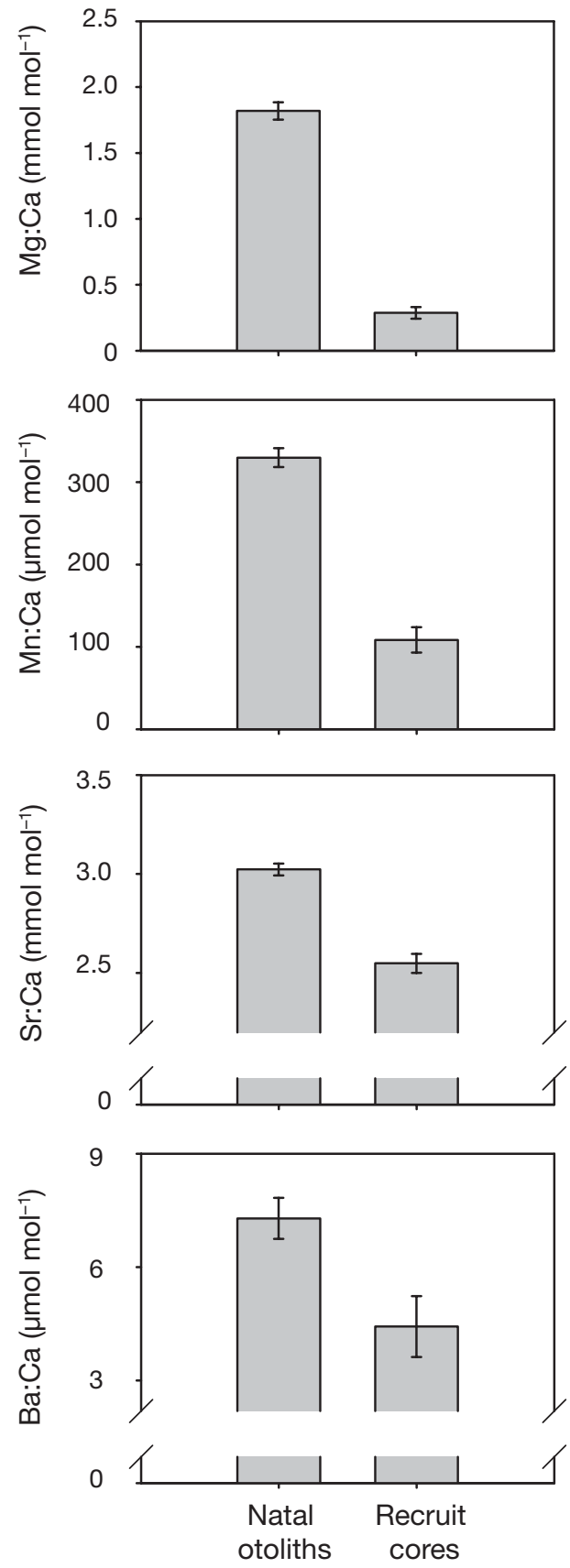

Fig. 5. Stegastes beebei. Mean levels of each element in natal otoliths and recruit cores. Differences between natal otoliths and recruit cores were significant $(p<0.01)$ for all elements. Error bars are $\pm 1 \mathrm{SE}$

maternal effects may be responsible. The strength of maternal effects are still unknown, and it is likely that a number of factors influence the way a mother provisions her young (McCormick 1999, Berkeley et al. 2004). If maternal provisioning affects the chemistry of natal otoliths, species that lay larger benthic eggs, such as damselfish, may have stronger maternal effects than 

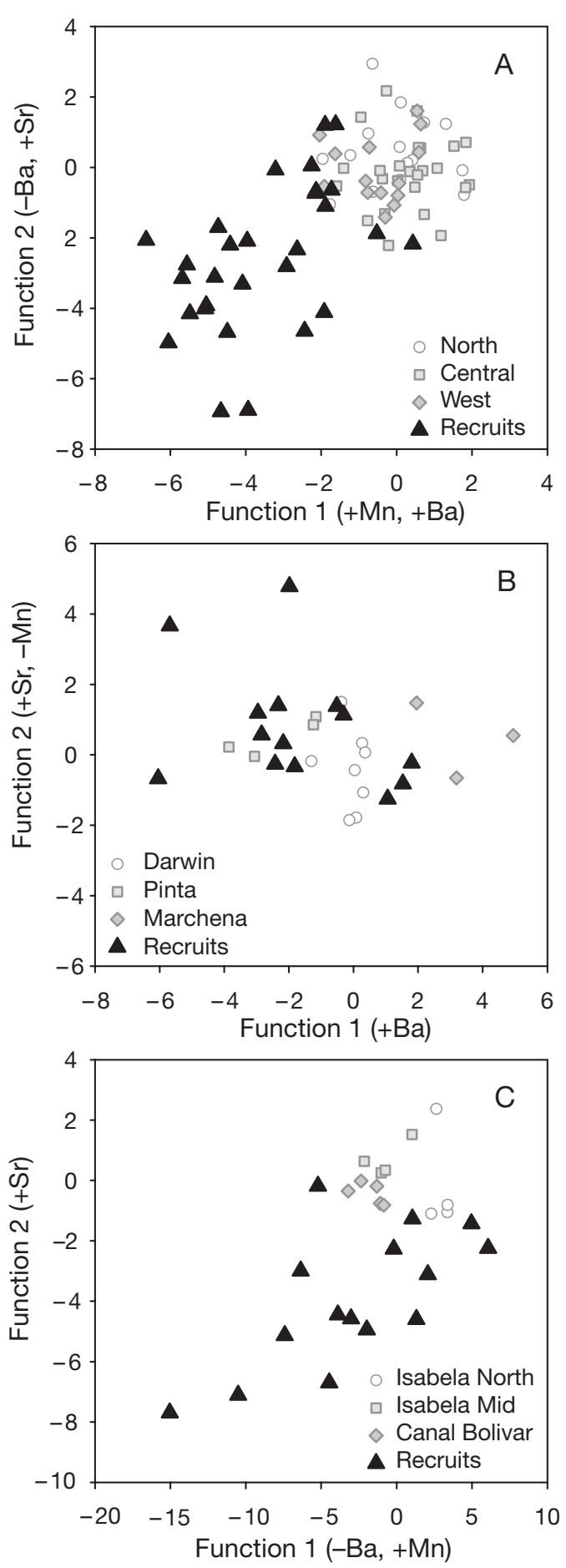

Fig. 6. Stegastes beebei. Discriminant Function Analysis of natal otoliths and classifications of recruit cores. The discriminant functions were generated using clutch means of $\mathrm{Sr}, \mathrm{Ba}$, and $\mathrm{Mn}$. Recruits cores were then classified using these discriminant functions. $\mathrm{Pb}$ was not used because it was below detection limits in recruit cores. (A) All clutches grouped by region, and all recruits. (B) Clutches and recruits from the North, with clutches grouped by island. (C) Clutches and recruits from the West, with clutches grouped by island. Jackknife values are: $47.2,73.3$ and $61.5 \%$ for (A-C), respectively. See Table 6 for discriminant function loadings those with smaller, pelagic eggs, but this idea has yet to be tested explicitly.

Contamination of samples could also create variation at the clutch level, but it is not likely the primary source of variation among clutches. First, we used previously published extraction protocols to prepare samples (Warner et al. 2005, Zacherl 2005). Second, certain elements may be more susceptible to contamination (e.g. $\mathrm{Pb}$ ), but other elements should be much less susceptible (e.g. Sr). However, we found significant clutch-level variation for all elements and there is now evidence that at least some elements in natal otoliths are maternally influenced (Thorrold et al. 2006). Strong maternal effects could generate significant among-clutch variation. Finally, any contamination would occur randomly, weakening any true spatial patterns. The fact that within-region spatial patterns were quite clear (e.g. reclassification rates to island of $\sim 75$ to $80 \%$ in the North and $\sim 66$ to $84 \%$ in the West) suggests that any contamination was minor. Therefore, we suggest that while unknown levels of contamination may occur during preparation of natal otoliths, contamination is likely to be low and maternal effects are more likely driving the overall patterns of clutchlevel variation that we observe.

Ultimately, variation in natal otolith signatures is only useful to track larval dispersal if the natal signature at a site matches the core of a recruit from that site. Therefore, there should be good correspondence in both univariate and multivariate patterns between natal otoliths and recruit cores, assuming that most individuals recruiting to the study area were not spawned at unsampled and chemically distinct natal sites. In our dataset, mean values for recruit cores were significantly lower than mean values of natal otoliths for all elements (Fig. 5), and many of the recruits fell outside of the DFA space occupied by the natal otoliths (Fig. 6).

It is possible that methodological factors may create differences between natal otoliths and recruit cores. All elements were measured in MR in recruit cores, while some ( $\mathrm{Sr}, \mathrm{Ba})$ were measured in LR in natal otoliths. However, the calculated concentrations we measured in the NIST 612 glass standard did not differ between LR and MR for any element. It is more likely that measurements of elemental concentrations in recruit cores are influenced by the ablation of noncore material along with the cores. Since levels of many of the elements detectable in otolith cores of Stegastes beebei are elevated relative to non-core regions of the otolith (Ruttenberg et al. 2005a), inclusion of non-core material in the ablation of the core would dilute the effective signal from the core. Even though we ablated the core using a series of small, individual pits, this method may ablate non-core 
material along with the core (Ruttenberg et al. 2005a), especially since the nominal beam width of the laser is approximately the same the size as natal otoliths $(\sim 20$ to $25 \mu \mathrm{m})$. Dilution of this core signal could account for some of the discrepancy between data from natal otoliths and data from otolith cores. A combination of a smaller beam width and fewer laser pulses may be required to reduce dilution of the core with non-core otolith material (Ruttenberg et al. 2005a).

In summary, we provide some guidelines and caveats on the use of otolith chemistry to track larval dispersal in a fully marine fish. We outline the steps that should be followed to undertake studies of this kind, including using natal otoliths to map variation in chemical signature at potential source sites, and plotting the cores of recruits in the space created by the natal otoliths. We found spatial variation in multi-element otolith signatures over smaller spatial scales (islands within region, clutches within islands) but not over larger scales (among regions). Since usable variation exists over smaller scales, we will only be able to use otolith chemistry to track larval dispersal in this system if the scale of dispersal matches this scale of chemical variation. At the moment, there is no information available that we might use to make this determination. Finally, we found that levels of a number of elements in the cores of newly settled recruits tend to be lower than those of natal otoliths. The mismatch may be due in part to methodology, but it is clear that additional work is required to address this issue. Methods in otolith chemistry have the potential to address questions of larval connectivity, but the results from this study highlight the fact that they must be applied cautiously and that additional methodological studies are required before we can successfully realize this potential.

Acknowledgements. Many thanks to the staff of the Charles Darwin Research Station for logistical support and the Galápagos National Park Service for permission to conduct this research. We are indebted to all of those who assisted with fieldwork, but especially to A. Haupt, without whom this work would have been impossible. We thank G. Paradis and M. Sheehy for assistance in the laboratory and W. White and J. Caselle for assistance with programming and statistics. Financial support was generously provided by the Partnership for Interdisciplinary Study of Coastal Oceans (PISCO), funded by the David and Lucille Packard Foundation, the UC Regents, a Fellowship for Coral Reef Research from the International Society for Reef Studies/The Ocean Conservancy, the Graduate Division of UCSB, the Explorers Club, the American Society of Ichthyologists and Herpetologists, the PADI Project AWARE Foundation, and Sigma Xi. We also thank S. Hamilton, J. Standish, S. Thorrold and S. Swearer for comments on earlier versions of the manuscript. This is PISCO contribution no. 218.

\section{LITERATURE CITED}

Bath GE, Thorrold SR, Jones CM, Campana SE, McLaren JW, Lam JWH (2000) Strontium and barium uptake in aragonitic otoliths of marine fish. Geochim Cosmochim Acta 64: 1705-1714

Becker BJ, Fodrie FJ, McMillan PA, Levin LA (2005) Spatial and temporal variation in trace elemental fingerprints of mytilid mussel shells: a precursor to invertebrate larval tracking. Limnol Oceanogr 50:48-61

Berkeley SA, Chapman C, Sogard SM (2004) Maternal age as a determinant of larval growth and survival in a marine fish, Sebastes melanops. Ecology 85:1258-1264

Brophy D, Jeffries TE, Danilowicz BS (2004) Elevated manganese concentrations at the cores of clupeid otoliths: possible environmental, physiological, or structural origins. Mar Biol 144:779-786

Caley MJ, Carr MH, Hixon MA, Hughes TP, Jones GP, Menge BA (1996) Recruitment and the local dynamics of open marine populations. Annu Rev Ecol Syst 27:477-500

Campana SE (1999) Chemistry and composition of fish otoliths: pathways, mechanisms and applications. Mar Ecol Prog Ser 188:263-297

Campana SE, Thorrold SR (2001) Otoliths, increments, and elements: keys to a comprehensive understanding of fish populations? Can J Fish Aquat Sci 58:30-38

Campana SE, Chouinard GA, Hanson JM, Frechet A (1999) Mixing and migration of overwintering Atlantic cod (Gadus morhua) stocks near the mouth of the Gulf of St. Lawrence. Can J Fish Aquat Sci 56:1873-1881

Elsdon TS, Gillanders BM (2003) Reconstructing migratory patterns of fish based on environmental influences on otolith chemistry. Rev Fish Biol Fish 13:219-235

Gillanders BM (2002) Connectivity between juvenile and adult fish populations: Do adults remain near their recruitment estuaries? Mar Ecol Prog Ser 240:215-223

Gillanders BM, Kingsford MJ (2000) Elemental fingerprints of otoliths of fish may distinguish estuarine 'nursery' habitats. Mar Ecol Prog Ser 201:273-286

Glynn PW, Wellington GM (1983) Corals and coral reefs of the Galápagos Islands. University of California Press, Berkeley, CA

Hoff GR, Fuiman LA (1995) Environmentally induced variation in elemental composition of red drum (Sciaenops ocellatus) otoliths. Bull Mar Sci 56:578-591

Jones GP, Milicich MJ, Emslie MJ, Lunow C (1999) Selfrecruitment in a coral reef fish population. Nature 402: 802-804

Jones GP, Planes S, Thorrold SR (2005) Coral reef fish larvae settle close to home. Curr Biol 15:1314-1318

Martin GB, Thorrold SR (2005) Temperature and salinity effects on magnesium, manganese, and barium incorporation in otoliths of larval and early juvenile spot Leiostomus xanthurus. Mar Ecol Prog Ser 293:223-232

McCormick MI (1999) Experimental test of the effect of maternal hormones on larval quality of a coral reef fish. Oecologia 118:412-422

Milton DA, Chenery SR (2001) Sources and uptake of trace metals in otoliths of juvenile barramundi (Lates calcarifer). J Exp Mar Biol Ecol 264:47-65

Milton DA, Chenery SR, Farmer MJ, Blaber SJM (1997) Identifying the spawning estuaries of the tropical shad, terubok Tenualosa toli, using otolith microchemistry. Mar Ecol Prog Ser 153:283-291

Palacios DM (2002) Factors influencing the island-mass effect of the Galapagos Archipelago. Geophys Res Lett 29: $2134-2137$ 
Rieman BE, Myers DL, Nielsen RL (1994) Use of otolith microchemistry to discriminate Oncorhynchus nerka of resident and anadromous origin. Can J Fish Aquat Sci 51:68-77

Rooker JR, Secor DH, Zdanowicz VS, De Metrio G, Relini LO (2003) Identification of Atlantic bluefin tuna (Thunnus thynnus) stocks from putative nurseries using otolith chemistry. Fish Oceanogr 12:75-84

Ruttenberg BI, Hamilton SL, Hickford MJH, Paradis GL, Sheehy MS, Standish JD, Ben-Tzvi O, Warner RR (2005a) Elevated levels of trace elements in cores of otoliths and their potential for use as natural tags. Mar Ecol Prog Ser 297:273-281

Ruttenberg BI, Haupt AJ, Chiriboga AI, Warner RR (2005b) Patterns, causes and consequences of regional ecological variation in a reef fish. Oecologia 145:394-403

Secor DH, Dean JM, Campana SE (1995) Recent developments in fish otolith research. University of South Carolina Press, Columbia, SC

Secor DH, Rooker JR, Zlokovitz E, Zdanowicz VS (2001) Identification of riverine, estuarine, and coastal contingents of Hudson River striped bass based upon otolith elemental fingerprints. Mar Ecol Prog Ser 211:245-253

Sokal RR, Rohlf FJ (1995) Biometry. 3rd edn. Freeman, New York

Swearer SE, Forrester GE, Steele MA, Brooks AJ, Lea DW (2003) Spatio-temporal and interspecific variation in otolith trace-elemental fingerprints in a temperate estuarine fish assemblage. Estuar Coast Shelf Sci 56:1111-1123

Thorrold SR, Jones CM, Swart PK, Targett TE (1998) Accurate classification of juvenile weakfish Cynoscion regalis to estuarine nursery areas based on chemical signatures in otoliths. Mar Ecol Prog Ser 173:253-265

Thorrold SR, Latkoczy C, Swart PK, Jones CM (2001) Natal

Editorial responsibility: Howard Browman (Associate Editorin-Chief), Storebø, Norway homing in a marine fish metapopulation. Science 291: 297-299

Thorrold SR, Jones GP, Planes S, Hare JA (2006) Trans-generational marking of embryonic otoliths in marine fishes using barium stable isotopes. Can J Fish Aquat Sci 63: 1193-1197

Tzeng WN, Tsai YC (1994) Changes in otolith microchemistry of the Japanese eel, Anguilla japonica, during its migration from the ocean to the rivers of Taiwan. J Fish Biol 45: 671-683

Warner RR, Cowen RK (2002) Local retention of production in marine populations: evidence, mechanisms, and consequences. Bull Mar Sci 70:245-249

Warner RR, Swearer SE, Caselle JE, Sheehy MS, Paradis GL (2005) Natal trace-elemental signatures in the otoliths of an open-coast fish. Limnol Oceanogr 50:1529-1542

Wellington GM, Strong AE, Merlen G (2001) Sea surface temperature variation in the Galapagos Archipelago: a comparison between AVHRR nighttime satellite data and in situ instrumentation (1982-1998). Bull Mar Sci 69:27-42

White JW, Ruttenberg BI (in press) Discriminant function analysis in marine ecology: some oversights and their solutions. Mar Ecol Prog Ser

Witman JD, Smith F (2003) Rapid community change at a tropical upwelling site in the Galapagos Marine Reserve. Biodivers Conserv 12:25-45

Zacherl DC (2005) Spatial and temporal variation in statolith and protoconch trace elements as natural tags to track larval dispersal. Mar Ecol Prog Ser 290:145-163

Zacherl DC, Paradis G, Lea DW (2003) Barium and strontium uptake into larval protoconchs and statoliths of the marine neogastropod Kelletia kelleti. Geochim Cosmochim Acta 67:4091-4099

Submitted: December 15, 2005; Accepted: May 13, 2006 Proofs received from author(s): November 21, 2006 